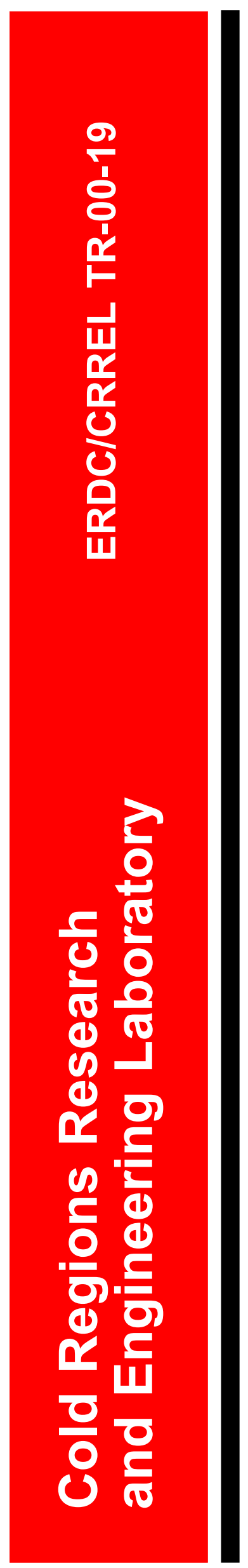

\title{
Frozen Soil Barriers for Explosives Containment
}

\author{
Giles M. Marion and Deborah K. Pelton
}

September 2000 


\section{Technical Report ERDC/CRREL TR-00-19}

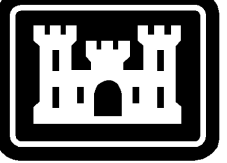

US Army Corps of Engineers ${ }_{\circledast}$

Cold Regions Research \& Engineering Laboratory

\section{Frozen Soil Barriers for Explosives Containment}

Giles M. Marion and Deborah K. Pelton 
Abstract: Explosives are a major contaminant of Department of Defense sites. Many uncertainties exist with respect to the mobility and stability of explosives in soils. The specific objectives of this work are to test the efficacy of frozen barriers to restrain movement of RDX, TNT, and picric acid through soils; test the concept of leaching contaminated soils above a frozen barrier as a method for soil cleanup; and compare the mobility and stability of explosives in an aged, field-contaminated soil versus a freshly contaminated soil. Two methods of adding explosives were examined. In Treatment 1, explosives were added in aqueous solution to a clean soil. In Treatment 2, explosives from an aged, field-contaminated soil were used. In Treatment 1, where the aqueous phase explosives were added above a stable frozen barrier, there was no significant movement of explosives into the frozen barrier. There was significant movement of explosives (picric acid $>$ RDX $\approx T N T$ ) into the frozen barrier in Treatment 2. However, this is believed to have occurred when the contaminated soil was added on top of the frozen soil, which caused a temporary thawing of the frozen barrier surface. A stable frozen barrier is effective in restraining the movement of RDX, TNT, and picric acid in soils. Water extractions of the field-contaminated soil recovered $44-56 \%$ of the picric acid, $11 \%$ of the TNT, and $4-5 \%$ of the RDX; only for the highly soluble picric acid would water extractions be a useful technique for cleanup of explosives in soils. About $88 \%$ of the TNT added in aqueous solution to Treatment 1 was missing at the end of the three-month experiment, demonstrating that there was a rapid transformation of TNT into unknown products or unextractable forms in soils.

How to get copies of CRREL technical publications:

Department of Defense personnel and contractors may order reports through the Defense Technical Information Center:

DTIC-BR SUITE 0944

8725 JOHN J KINGMAN RD

FT BELVOIR VA 22060-6218

Telephone (800) 225-3842

E-mail help@dtic.mil msorders@dtic.mil

WWW http://www.dtic.mil/

All others may order reports through the National Technical Information Service:

NTIS

5285 PORT ROYAL RD

SPRINGFIELD VA 22161

Telephone (703) 487-4650

(703) 487-4639 (TDD for the hearing-impaired)

E-mail_orders@ntis.fedworld.gov

WWW http://www.ntis.gov/index.html

A complete list of all CRREL technical publications is available from USACRREL (CEERD-IM-HL)

72 LYME RD

HANOVER NH 03755-1290

Telephone (603) 646-4338

E-mail_erhoff@crrel.usace.army.mil

For information on all aspects of the Cold Regions Research and Engineering Laboratory, visit our World Wide Web site:

http://www.crrel.usace.army.mil 


\section{PREFACE}

This report was prepared by Dr. Giles M. Marion, Research Physical Scientist, and Deborah K. Pelton, Research Technician, Geochemical Sciences Division, U.S. Army Cold Regions Research and Engineering Laboratory (CRREL), Engineer Research and Development Center (ERDC), Hanover, New Hampshire.

This work was funded by Department of Defense BT-25 project Air, Snow, Ice, and Soil Interactions in Cold Regions.

Technical reviews for this report were provided by Dr. Alex Iskandar and Dr. Paul H. Miyares, CRREL.

The authors thank Philip G. Thorne for providing technical advice throughout this experiment.

This publication reflects the personal views of the authors and does not suggest or reflect the policy, practices, programs, or doctrine of the U.S. Army or government of the United States. The contents of this report are not to be used for advertising or promotional purposes. Citation of brand names does not constitute an official endorsement or approval of the use of such commercial products. 


\title{
Frozen Soil Barriers for Explosives Containment
}

\author{
GILES M. MARION AND DEBORAH K. PELTON
}

\section{INTRODUCTION}

Explosives are a major contaminant of Department of Defense (DoD) sites. Explosives enter soil and water at production facilities, solid waste destruction sites, packing and warehouse facilities, and from dispersed exploded and unexploded ordnance (McGrath 1995, Brannon et al. 1997, Hundal et al. 1997). Many explosives are mutagenic, carcinogenic, or otherwise toxic for plants and animals (Pennington and Patrick 1990, Bradley et al. 1994, Comfort et al. 1995). Cleanup of explosives-contaminated sites is a major DoD priority.

The mobility of explosives in soils is governed by 1) advective-dispersive transport, 2) solubility, 3) sorption, 4) volatilization, 5) biotransformation, and 6) abiotic processes (Selim and Iskandar 1994, McGrath 1995, Brannon et al. 1997). The solubilities of RDX, TNT, and picric acid are 45, 150, and $12,400 \mathrm{mg} \mathrm{L}^{-1}$ at $25^{\circ} \mathrm{C}$ (McGrath 1995). Grant et al. (1995) demonstrated that freshly added nitramines (e.g., RDX) were stable over an eight-week period at all storage temperatures; freshly added nitroaromatics (e.g., TNT) degraded rapidly at room temperature and more slowly under refrigeration. In contrast, both nitramines and nitroaromatics were quite stable in aged, field-contaminated soils.

Soil freezing has been examined as a means for concentrating explosives and heavy metals as well as a barrier to prevent migration of hazardous wastes (Ayorinde et al. 1989, Boitnott et al. 1997, Iskandar and Sayles 1997). Because of the high solubility and ionic nature of explosives such as picric acid, there is concern that such explosives might leach into frozen barriers.

There are many uncertainties with respect to the mobility and stability of explosives in soils. The specific objectives of this work are to 1) test the efficacy of frozen barriers in restraining the movement of RDX,
TNT, and picric acid in soils; 2) test the concept of leaching contaminated soils above a frozen barrier as a method for soil cleanup; and 3) compare the mobility and stability of explosives in an aged, field-contaminated soil versus a freshly contaminated soil.

\section{METHODS AND MATERIALS}

\section{Soil preparation}

Clean soil (a sandy silt made from a mixture of Windsor silt loam and a sand) was prepared by air drying, sieving through a standard \#40 sieve, and adding sufficient water to reach approximately $20 \%$ moisture content. The clean soil was thoroughly mixed and stored in the refrigerator for several days to equilibrate with respect to moisture.

Explosives soils contaminated with RDX, TNT, or picric acid were collected from the field during previous studies conducted at CRREL. Picric acid soils were from Hawthorne Army Ammunition Plant, Nevada; TNT soils were from Volunteer Army Ammunition Plant, Tennessee; and RDX soils were from Newport Army Ammunition Plant, Indiana. Each soil was air-dried and sieved through a standard \#40 sieve prior to weighing and mixing. The RDX portion of the contaminated soil mixture was made from three separate samples to obtain sufficient quantities for our target concentrations (Table 1). The TNT- and picric-acid-contaminated soils were mixed with the RDX soil, and the resulting explosivescontaminated mixture was diluted with clean soil. Sufficient water was added to the contaminated soil mixture to reach a moisture content of approximately $20 \%$. The moist soil was thoroughly mixed and stored in the refrigerator for several days to equilibrate with respect to moisture. 


\begin{tabular}{|c|c|c|c|c|c|}
\hline Soil & $\begin{array}{c}\text { Concentration }^{*} \\
(\mu \mathrm{g} / \mathrm{g})\end{array}$ & $\begin{array}{l}\text { Soil mass } \\
\text { (g) }\end{array}$ & $\begin{array}{l}\text { Mass of } \\
\text { explosives } \\
(\mu g)\end{array}$ & $\begin{array}{c}\text { Target } \\
\text { concentration } \\
(\mu \mathrm{g} / \mathrm{g})\end{array}$ & $\begin{array}{c}\text { Measured } \\
\text { concentration } \\
(\mu \mathrm{g} / \mathrm{g})\end{array}$ \\
\hline $\begin{array}{l}\text { Clean soil } \\
\text { RDX soils }\end{array}$ & 0 & $1,348.72$ & 0 & 0 & \\
\hline \#9 & 1,800 & 9.52 & 17,130 & & \\
\hline$\# 10$ & 3,170 & 6.17 & 19,548 & & \\
\hline \#11 & 12,200 & 6.83 & 83,383 & & \\
\hline RDX & & 22.52 & 120,061 & 80.35 & 85.81 \\
\hline TNT & 12,200 & 10.13 & 123,586 & 82.71 & 77.99 \\
\hline $\begin{array}{l}\text { Picric acid } \\
\text { Soil mixture }\end{array}$ & 1,000 & $\begin{array}{r}112.88 \\
1494.25\end{array}$ & 112,880 & 75.54 & 120.26 \\
\hline
\end{tabular}

\begin{tabular}{|c|c|c|c|}
\hline Explosive & $\begin{array}{c}\text { Mass added } \\
\text { to } 4 \text { L of water } \\
\text { (g) }\end{array}$ & $\begin{array}{c}\text { Target } \\
\text { concentration } \\
(m g / L)\end{array}$ & $\begin{array}{c}\text { Measured } \\
\text { concentration* } \\
(\mathrm{mg} / \mathrm{L})\end{array}$ \\
\hline RDX & 0.2231 & 55.8 & $40.8 \pm 1.7$ \\
\hline TNT & 0.2939 & 73.5 & $73.2 \pm 2.3$ \\
\hline Picric acid & 0.4004 & 100.1 & $78.1 \pm 5.0$ \\
\hline
\end{tabular}

\section{Aqueous solution preparation}

An aqueous explosives solution was prepared by adding TNT, RDX, and picric acid to $4 \mathrm{~L}$ of Type I water. This solution was stored in a brown bottle to reduce photodegradation of TNT. The solution was stirred for several days to ensure maximum dissolution of each component. Target and measured concentrations of explosives in the aqueous solution are reported in Table 2.

\section{Experimental chambers}

The experimental setup (Boitnott et al. 1997) consisted of four sealed cylindrical chambers made of Plexiglas, $15.2 \mathrm{~cm}$ high and $7.6 \mathrm{~cm}$ in diameter, sitting on a laboratory benchtop (Fig. 1). Insulated copper freezing coils surrounded the bottom half of each chamber; ethylene glycol from a constant temperature bath $\left(-15^{\circ} \mathrm{C}\right)$ was circulated through the coils to freeze the soil. Ethylene glycol from a second temperature bath $\left(10^{\circ} \mathrm{C}\right)$ circulated through an additional copper coil resting on top of the freezing coils to act as a transition zone for temperature change between the frozen and unfrozen layers.

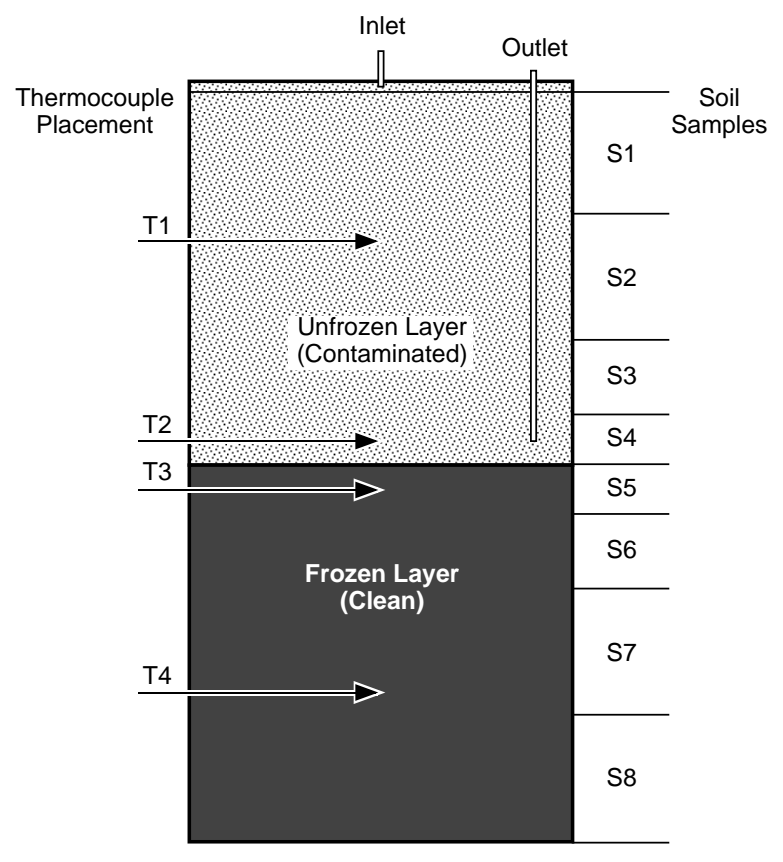

Figure 1. Experimental chambers. 
The bottom half of each chamber was packed with the clean moist soil by adding $1.0 \mathrm{~cm}$ of soil at a time, packing it down, then scoring the soil surface before adding the next layer. Thermocouples were placed in the center of each chamber and packed into the soil at approximately $12 \mathrm{~cm}$ and $8 \mathrm{~cm}(0.5 \mathrm{~cm}$ below the frozen layer boundary) from the top of the chambers. After the bottom half of each chamber was finished, the soils were frozen.

Once the soil in the bottom was frozen, soil was packed into the top half of each chamber. Chambers 1 and 3 were packed with clean soil, and Chambers 2 and 4 were packed with contaminated soil. The filtered end of the outlet tube was packed in the soil just above the frozen layer. Thermocouples were packed into the soil at about $7 \mathrm{~cm}(0.5 \mathrm{~cm}$ above frozen layer boundary) and $3 \mathrm{~cm}$ from the top.

The freezing coil bath was set to a temperature of $-10^{\circ} \mathrm{C}$ to freeze the soil to a temperature of about -2 to $-3^{\circ} \mathrm{C}$. Soil temperatures in the bottom of each chamber fell below zero after approximately 3.5 days and remained at -2 to $-3^{\circ} \mathrm{C}$ for four days. When the unfrozen top soil layer was added, the bottom soil warmed to above freezing except for the very bottom layer (below $12 \mathrm{~cm}$ ) and remained above freezing for approximately three days. To bring temperatures back down to about $-3^{\circ} \mathrm{C}$, the bath was turned down to $-15^{\circ} \mathrm{C}$.

\section{Temperature measurements}

Temperature data were recorded continually throughout the experiment using two Omnidata Recorders beginning on Day 1. One recorder was used for Chambers 1 and 2; the other for Chambers 3 and 4. Each data logger recorded temperatures for the four thermocouples packed in each chamber plus a thermocouple sitting on the benchtop to monitor air temperatures. The average of 15-minute readings was recorded every two hours until the end of the experiment on Day 100. In addition, temperatures were monitored and recorded in the laboratory notebook daily. Because of problems with the data logger for Chambers 1 and 2, continual readings were not recorded from Day 1 to Day 32; however, the daily checks provided values for comparison to continual readings for Chambers 3 and 4 .

\section{Solution sampling}

The initial volume of solution was added to the chambers on Day 13, two weeks after the chambers were packed with soil. The aqueous explosives solution was added to the clean soil, and distilled water was added to the contaminated soil by slowly dripping the solutions into the top of each chamber through an inlet (Fig. 1).

Using a hand pump attached to the outlet, solutions

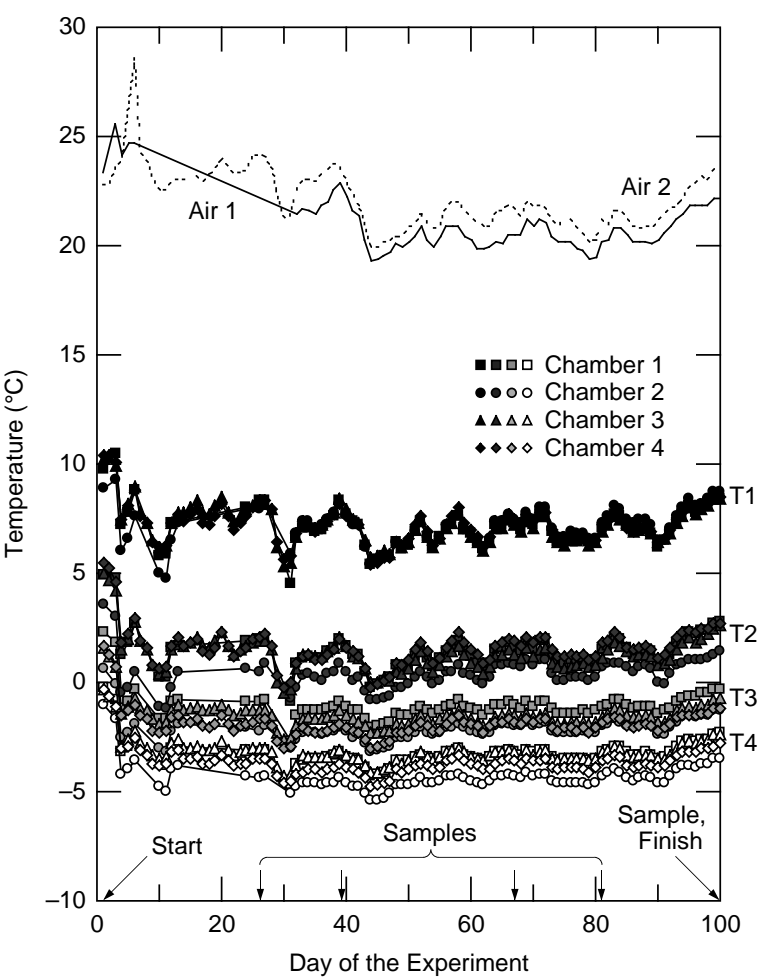

Figure 2. Temperatures measured in room air and in chambers during the experiment.

were extracted from above the frozen soil barrier through a filter on the bottom of the outlet. Samples were collected on Days 26, 39, 67, 81, and 100 (Fig. 2 ). Each time that solution was collected for analysis of explosives, a new volume of solution was added to the soil. Sampling dates, as well as volumes added and removed, are reported in Table 3.

\section{Chamber soil sampling}

At the end of the experiment, the chambers were sampled by removing the soil in layers. Eight soil layers were collected: four layers each from the top and bottom halves of the chambers (Fig. 1). The soils were removed by carefully scraping out from the top down using a ruler to guide the removal. Two subsamples of each soil layer were analyzed for air-dried moisture content and subsequently analyzed for concentrations of explosives.

\section{Chemical analyses}

If necessary to bring samples into the concentration range of the standards, aqueous solutions of explosives were diluted with Milli-Q water. Then they were filtered through a $0.5-\mu \mathrm{m}$ filter into sample vials prior to analysis.

Explosives were extracted from soil samples following the SW-846 Method 8330 for RDX and TNT (USEPA 1994), and Thorne and Jenkins (1995) for pi- 


\begin{tabular}{|c|c|c|c|}
\hline $\begin{array}{l}\text { Sample } \\
\text { date }\end{array}$ & Chamber & $\begin{array}{l}\text { Volume added } \\
\qquad(m L)\end{array}$ & $\begin{array}{c}\text { Volume removed } \\
(\mathrm{mL})\end{array}$ \\
\hline 13 & $\begin{array}{l}1 \\
2 \\
3 \\
4\end{array}$ & $\begin{array}{l}25.2 \\
27.4 \\
19.2 \\
17.4\end{array}$ & \\
\hline 26 & $\begin{array}{l}1 \\
2 \\
3 \\
4\end{array}$ & $\begin{array}{l}37.5 \\
25.8 \\
36.4 \\
28.2\end{array}$ & $\begin{array}{l}42.0 \\
28.0 \\
33.5 \\
30.0\end{array}$ \\
\hline 39 & $\begin{array}{l}1 \\
2 \\
3 \\
4\end{array}$ & $\begin{array}{l}38.1 \\
26.0 \\
37.6 \\
26.0\end{array}$ & $\begin{array}{l}35.0 \\
25.0 \\
36.0 \\
26.0\end{array}$ \\
\hline 67 & $\begin{array}{l}1 \\
2 \\
3 \\
4\end{array}$ & $\begin{array}{l}36.3 \\
33.0 \\
36.6 \\
30.8\end{array}$ & $\begin{array}{l}35.5 \\
26.0 \\
35.0 \\
26.5\end{array}$ \\
\hline 81 & $\begin{array}{l}1 \\
2 \\
3 \\
4\end{array}$ & $\begin{array}{l}40.0 \\
21.2 \\
34.1 \\
26.2\end{array}$ & $\begin{array}{l}37.5 \\
20.0 \\
34.0 \\
27.0\end{array}$ \\
\hline 100 & $\begin{array}{l}1 \\
2 \\
3 \\
4\end{array}$ & & $\begin{array}{l}41.0 \\
27.0 \\
37.0 \\
28.0\end{array}$ \\
\hline Totals & $\begin{array}{l}1 \\
2 \\
3 \\
4\end{array}$ & $\begin{array}{l}177.1 \\
133.4 \\
163.9 \\
128.6\end{array}$ & $\begin{array}{l}191.0 \\
126.0 \\
175.5 \\
137.5\end{array}$ \\
\hline
\end{tabular}

cric acid. Two 2-g subsamples of air-dried soil were each placed in a $20-\mathrm{mL}$ glass vial. Ten $\mathrm{mL}$ of acetonitrile was added to one vial of soil to extract RDX and TNT, while $10 \mathrm{~mL}$ of Milli-Q water was added to the other vial of soil to extract picric acid. The vials were placed in an ultrasonic bath overnight to ensure maximum recovery of explosives from soil. To flocculate solids after sonicating, $10 \mathrm{~mL}$ of a $\mathrm{CaCl}_{2}$ solution was added to the vials with acetonitrile, and $10 \mathrm{~mL}$ of acetonitrile was added to the vials with water. All samples were centrifuged at 1500 RPM for five minutes and filtered through a $0.5-\mu \mathrm{m}$ filter into sample vials. Centrifugation was used to facilitate sample flocculation.*

Analyses of explosives and their transformation products in aqueous solutions and soil extracts were performed by reverse-phase, high-performance liquid

\footnotetext{
* Personal communication, Philip G. Thorne, Geological Sciences
} Division, CRREL, Hanover, New Hampshire, 1999. chromatography (RP-HPLC) (Thermoseparation Products) on a 25- $\times 4.6-\mathrm{cm}$ LC-18 (Supelco) column. Samples were mixed 50:50 with acetonitrile prior to analysis. The analytes were eluted with $35: 65(\mathrm{v} / \mathrm{v})$ methanol:aqueous buffer $\left(100 \mathrm{mmol} \mathrm{KH}_{2} \mathrm{PO}_{4}\right)$ adjusted to $\mathrm{pH} 3.5$ with acetic acid. Flow rate was $1.5 \mathrm{~mL}$ $\mathrm{min}^{-1}$. A standard solution containing RDX, TNT, HMX, TNB, and 2 amino-DNT at concentrations of 1 $\mathrm{mg} \mathrm{L}^{-1}$ in acetonitrile was prepared following SW-846 Method 8330 (USEPA 1994). A standard solution of picric acid in water at a concentration of $5 \mathrm{mg} \mathrm{L}^{-1}$ was prepared according to Thorne and Jenkins (1995).

\section{Mass balance calculations}

To calculate a mass balance of explosives in the chambers, all concentrations were converted to mass units $(\mu \mathrm{g})$. For the aqueous solutions, the following equation was used:

$$
\begin{aligned}
& \text { mass of explosive }(\mu \mathrm{g})= \\
& \quad \text { concentration of explosive }\left(\mathrm{mg} \mathrm{L}^{-1}\right) \\
& \times \text { volume of solution added (input) or } \\
& \text { removed (output) }(\mathrm{L}) \\
& \times 1000 .
\end{aligned}
$$

There was some error associated with the volume of solution removed because some solution remained in the extraction tube. The volume of solution added was determined using a buret. To calculate the mass of explosives in the soil, the following equation was used:

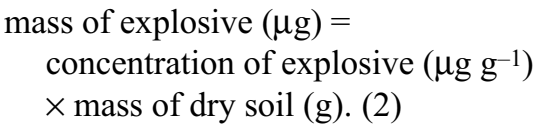

The mass of dry soil was estimated based on the weight and moisture content of soil added at the beginning of the experiment. Soil was packed into the chambers in approximately $1-\mathrm{cm}$ layers and was collected from the chambers in $2.5-\mathrm{cm}, 1.5-\mathrm{cm}$, or 1-cm layers (Fig. 1). The dry weights of soil, determined at the beginning of the experiment for each 1-cm layer, were added together to get the dry weight of the final sample.

\section{RESULTS}

\section{Temperature profiles}

Part of the technical challenge of this experiment was to maintain a stable frozen barrier in the base of the experimental chambers (Fig. 1). Temperature measurements at the four levels in the chambers (T1T4) averaged $\approx 7^{\circ}, 1^{\circ},-1.5^{\circ}$, and $-3.5^{\circ} \mathrm{C}$, respectively (Fig. 2). The temperatures in the chambers fluctuated with changes in room air temperature. During the course 
of the experiment, the frozen layer occasionally moved upward in the chamber. On Days 30-31, T2 was frozen in all four chambers (Fig. 2). T2 in Chamber 2 was frequently frozen.

Of more concern than movement of the frozen zone upward was thawing downward. At the beginning of the experiment (Days 1-3), temperatures measured at T3 were $>0^{\circ} \mathrm{C}$ in all chambers. This short-term thaw occurred when warmer soil was packed on top of the frozen base. This was a problem for the field-contaminated soils (Treatment 2) because thawing of the frozen barrier allowed movement of explosives from the upper contaminated soil into what should have been a frozen barrier. This was not a problem for Treatment 1 , where explosives were introduced in the aqueous phase for the first time on Day 13 (Table 3) after the chambers had refrozen (Fig. 2).

\section{Aqueous phase concentrations}

The concentrations of RDX, TNT, and picric acid in the periodic aqueous extractions in the columns of Treatment 1 slowly increased during the experiment (Fig. 3 ). In Treatment 2, aqueous extract RDX, picric acid, and TNT concentrations slowly decreased. By the end of the experiments, all aqueous phase explosives concentrations ranged from 10 to $100 \mathrm{mg} \mathrm{L}^{-1}$. For both treatments, the greater solubility of picric acid relative to RDX and TNT was apparent in the higher concentrations of picric acid in the aqueous extracts. There was little variability within the two replicates as judged by the low standard errors, especially in the later samplings (Fig. 3).

\section{Solid phase concentrations}

At the end of the experiments the soil chambers were sliced into eight layers (Fig. 1) that were analyzed for RDX, picric acid, TNT, and explosives transformation products.

In Treatment 1 (aqueous addition of explosives), significant amounts of RDX and picric acid were recovered in the unfrozen layers (Fig. 4a,c). There was little TNT recovered in the soil samples. No TNT degradation products (TNB, amino-DNT) were detected, suggesting that the TNT was either rapidly transformed or rendered unextractable. In Treatment 1 , there was no significant leaching of explosives into the frozen layer.

In contrast, significant amounts of explosives, especially picric acid, leached into the frozen layers in Treatment 2 (solid phase addition of explosives) (Fig. 4b,d). This was readily apparent even without chemical analyses, as the frozen layers were colored by the telltale yellow of picric acid. This leaching was probably due to thawing of the frozen soil layer when the contaminated, unfrozen soil layers were placed in the chambers above the frozen soil. Although thawing also occurred in Treatment 1, this occurred before the explosives were added; by the time the explosives were added (Day 13), the soils had refrozen (Fig. 2). Also in contrast to Treatment 1, Treatment 2 retained significant amounts of TNT in the contaminated soil layers (Fig. 4b,d). Note the difference in scale between Treatments 1 and 2; there was an approximately 4.6-fold greater amount of explosives in Treatment 2 than in Treatment 1 (Fig. 4).

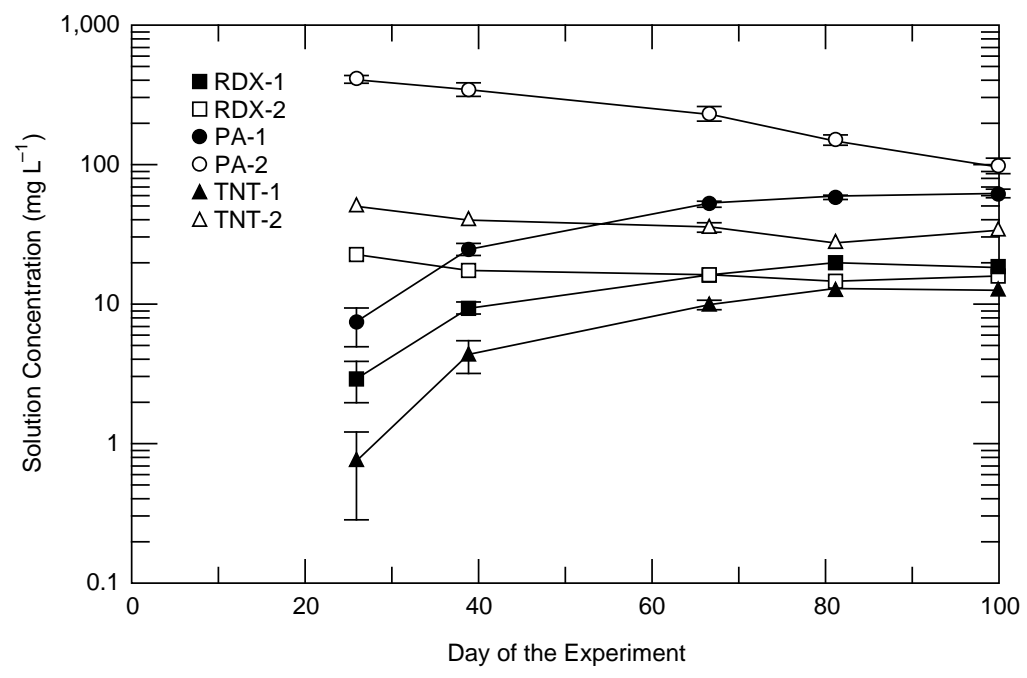

Figure 3. Concentrations of RDX, picric acid, and TNT in the aqueous extractions. 


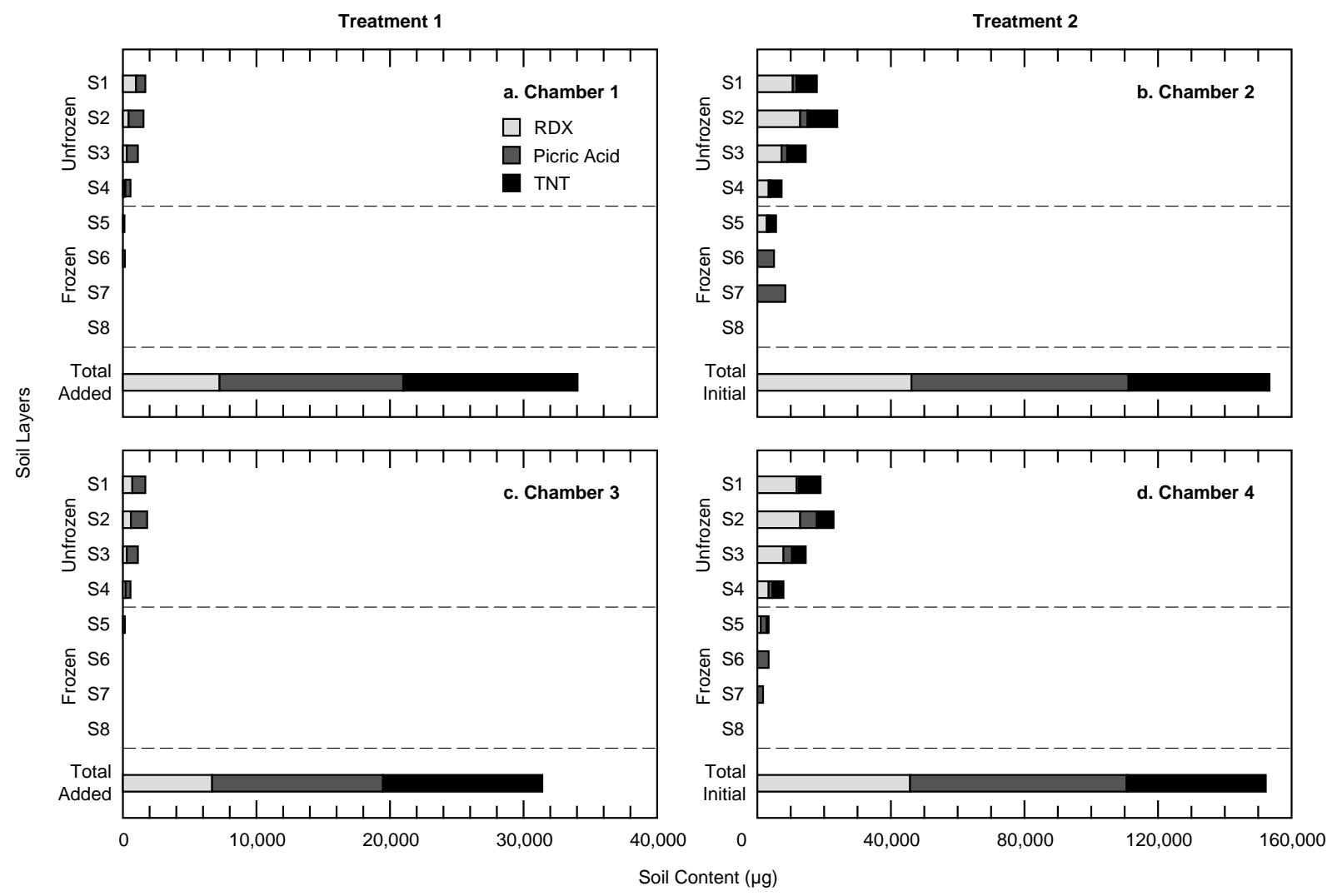

Figure 4. Distribution of RDX, picric acid, and TNT in soil layers at the experiments' conclusion.

\section{Mass balance}

At the end of the experiments, an effort was made to account for the mass of explosives either initially present in the chambers as contaminated soil (Treatment 2) or added to the chambers as contaminated solution (Treatment 1). Compartments were aqueous (recovered in periodic samplings), unfrozen soil, frozen soil, and "missing" (the difference between what was present initially or added and the final recovery). The recovery patterns were similar within treatments, but quite dissimilar between treatments (Fig. 5).

In Treatment 1 (Chambers 1 and 3), there were similar amounts of $\operatorname{RDX}(\approx 33 \%)$ in the aqueous, unfrozen soil, and missing compartments; almost no RDX leached into the frozen soil compartment. In contrast, for Treatment 2 (Chambers 2 and 4), about $75 \%$ of the RDX was found in the unfrozen soil; little RDX was removed with the periodic aqueous phase samplings. The amount that was missing in Treatment $2(15 \%)$ was about half of the missing compartment of Treatment 1 . There was minor movement of the RDX into the frozen soil layers in Treatment 2 due to thawing of the frozen layer when explosives were added.

Because of the high solubility of picric acid $(12,400$ $\left.\mathrm{mg} \mathrm{L}^{-1}\right)$ relative to RDX (45 $\left.\mathrm{mg} \mathrm{L}^{-1}\right)$ and TNT (150 mg
$\left.\mathrm{L}^{-1}\right)$, a high percentage of picric acid $(45-60 \%)$ was recovered during the periodic samplings of the aqueous phase for both treatments (Fig. 5b). A significant amount of picric acid leached into the frozen soil layer in Treatment 2, again because of the thawing of this layer when the contaminated soil was added. In contrast, little of the highly soluble picric acid leached into the frozen soil in Treatment 1, where the explosives were added in aqueous solution after stabilization of the frozen barrier. Similar amounts (18-25\%) of picric acid were missing in the two treatments (Fig. 5b).

Approximately $12 \%$ of the TNT in Treatment 1 was recovered in the aqueous phase; virtually everything else was missing (Fig. 5c). In Treatment 2, about 56\% of the TNT originally present in the contaminated (unfrozen) soil remained in these soil layers at the conclusion of the experiments. About $12 \%$ of the TNT in Treatment 2 was recovered in the aqueous phase. A small amount of TNT leached into the frozen soil in Treatment 2, and about $30 \%$ was missing (Fig. 5c).

\section{DISCUSSION}

\section{Efficacy of frozen barriers}

Ideally, frozen barriers for restraining explosives 


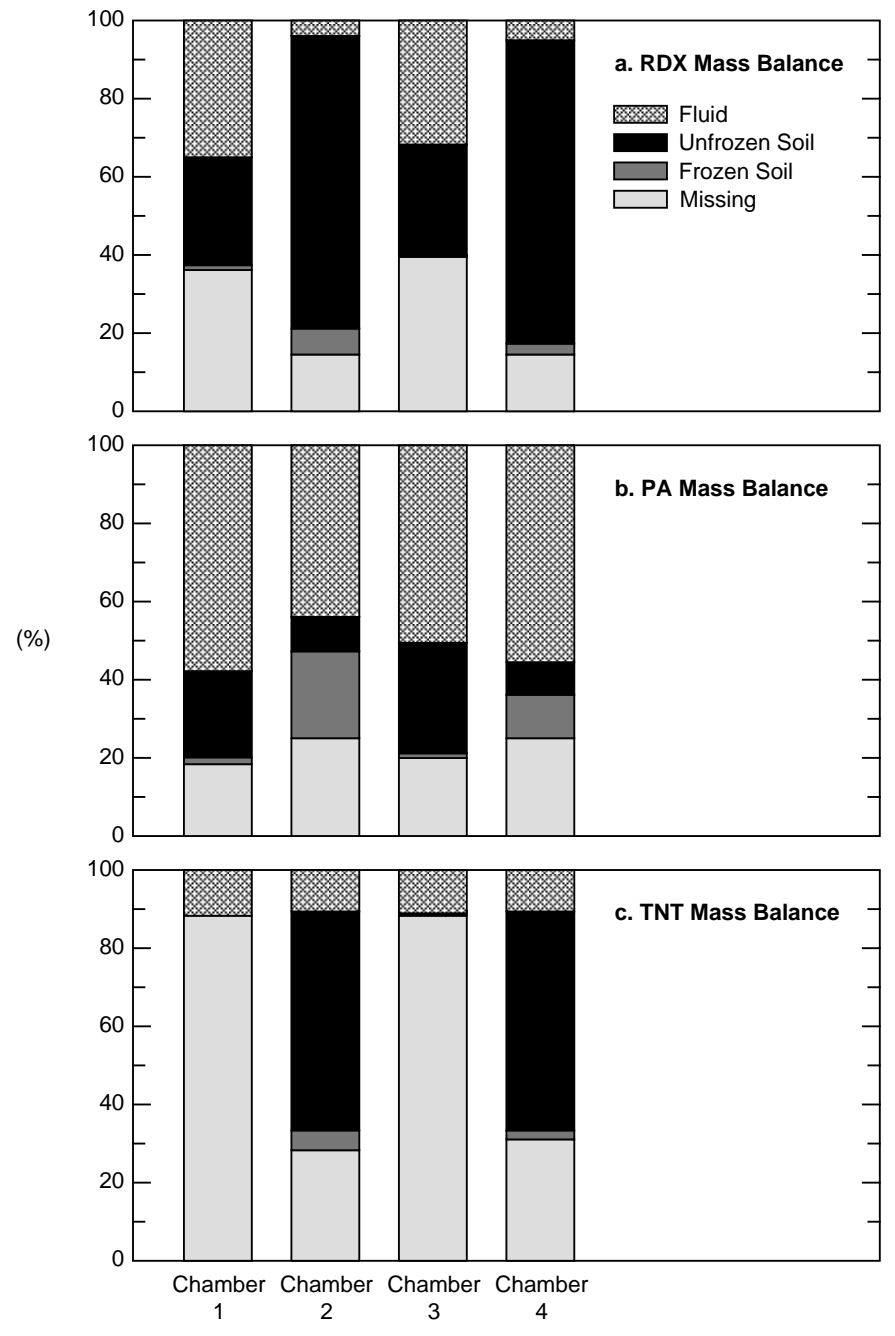

Figure 5. Distribution of added explosives at the experiments' conclusion.

should exclude explosives from the ice phase. Taylor (1989) has estimated partition coefficients $\left(c_{\mathrm{i}} / c_{\mathrm{w}}\right)$ for $\operatorname{RDX}\left(6.06 \times 10^{-3}\right)$ and TNT $\left(1.07 \times 10^{-3}\right)$ that indicate that ice efficiently excludes RDX and TNT. Slow freezing of soil to concentrate explosives such as TNT and RDX in the unfrozen "brine" has been attempted (Ayorinde et al. 1989). In that trial, there was insignificant movement $(<10 \%)$ of TNT and RDX.

There was significant movement of explosives into the frozen barrier in Treatment 2 (Fig. 4b,d); however, we believe that this occurred as the result of thawing of the frozen soil layers that occurred when the unfrozen soil material was added (Fig. 2). Insignificant amounts of explosives leached into the frozen barrier in Treatment 1 , where the explosives were added in aqueous solution onto a stable frozen soil (Fig. 4a,c).

In the "real world," problems can occur in maintaining a stable frozen barrier because of fluctuations in electrical power or ambient temperature (Fig. 2). As a consequence, the movement of explosives into temporarily unfrozen soil is an important consideration. It was clear from our experiments that this mobility into the temporarily unfrozen soil fell in approximately the same order as the solubility of explosives where picric acid $>>\mathrm{RDX} \approx$ TNT (Fig. 4, 5). For highly soluble explosives such as picric acid, a thicker frozen barrier may be necessary to ensure containment.

\section{Sequential extractions}

In earlier work, Boitnott et al. (1997) examined the effectiveness of a frozen barrier to contain heavy-metal-laden soil during remediation by sequential extraction with ethylene diamine tetraacetic acid (edetic acid, EDTA). They found that over $90 \%$ of the $\mathrm{Cu}$ and $\mathrm{Zn}$ and over $80 \%$ of the $\mathrm{Cd}$ and $\mathrm{Ni}$ was removed during sequential extractions.

In our work with explosives, $4-5 \%$ of the RDX was recovered from the field-contaminated soil (Chambers 2 and 4) with aqueous extractions (Fig. 5a); $44-56 \%$ of the picric acid was recovered (Fig. $5 b$ ); and $11 \%$ of the TNT was recovered (Fig. 5c). As a technique for cleaning an explosives-contaminated soil, aqueous extractions were effective in removing only the highly soluble picric acid. Other extractants such as acetone or acetonitrile would probably be more effective in extracting insoluble explosives such as RDX and TNT. Mobility of explosives in soils is highly sensitive to the extractant (Selim and Iskandar 1994).

The greater effectiveness of the EDTA heavymetal extractions versus the aqueous-explosives extractions was probably due to differences in solubility and mobility. The concentration of heavy metals was always highest at the ice interface. This indicates that the heavy-metal complexes were free to move toward the ice interface where chemical potentials should be lowest and thereby serve as a sink for heavy metals (Marion 1995). The distribution of explosives, on the other hand, showed no concentration increase at the ice interface. Instead concentrations were highest in the upper soil layers (Fig. 4), suggesting that the explosives were not mobile and the aqueous extractions simply removed the explosives from the lower unfrozen layers where the sampling outlet was located (Fig. 1).

\section{Stability of explosives}

Grant et al. (1995) found that added nitramines (e.g., RDX) were stable over an eight-week period at all storage temperatures; but, added nitroaromatics (e.g., TNT) degraded rapidly at room temperature and more slowly 
under refrigeration. In contrast, both nitramines and nitroaromatics were quite stable under refrigeration in four field-contaminated soils. When three of these fieldcontaminated soils were fortified with TNT, rapid degradation of TNT occurred under refrigeration. Our experiments demonstrated that fresh additions of TNT to soils were more subject to being degraded, being transformed, being rendered unextractable, or some combination of these processes than were field-aged, contaminated soils. We found no immediate degradation products of TNT ( 2 amino-DNT, 4 amino-DNT). This was true for both aqueous and soil extracts in both Treatments 1 and 2. Grant et al.'s (1995) paper is especially relevant to our study as their refrigeration temperature $\left(4^{\circ} \mathrm{C}\right)$ is similar to our unfrozen layer temperature $\left(0-8^{\circ} \mathrm{C}\right)$ (Fig. 2). However, one potentially significant difference between the studies is that their study was done under aerobic conditions while our study was done under anaerobic (moisture-saturated) conditions. In one soil, they found the complete loss of TNT within six days; however, amino-DNT was easily detected in this soil across the 56 days of the experiment. The total soil TNT concentration in the Grant study was $1.0 \mathrm{mg} / \mathrm{kg}$, which is much lower than our total addition of $25 \mathrm{mg} /$ $\mathrm{kg}$ in five additions of $5 \mathrm{mg} / \mathrm{kg}$ (see below). If TNT were degrading in our studies with five times more TNT than the Grant study, then we should have seen degradation products; or, the degradation process was so rapid, perhaps in combination with soil binding, as to be undetectable.

Another possible explanation for the missing TNT is that the quantities in the aqueous additions were diluted to below the detection limits when combined with the soil. In Chambers 1 and 3, a total of 14.0 and $12.8 \mathrm{mg}$ of TNT was added in five additions to the unfrozen soil layers that contained $520 \mathrm{~g}$ soil; the overall soil concentrations of TNT in Chambers 1 and 3 were therefore, respectively, 26.9 and $24.7 \mathrm{mg} / \mathrm{kg}$ (assuming a uniform distribution). The Method 8330 quantitation limit is $0.25 \mathrm{mg} / \mathrm{kg}$ (USEPA 1994), so we should have easily seen the TNT if present. In a few cases, we did detect barely measurable soil TNT concentrations in Chambers 1 and 3 . However, the amounts detected were minor compared to the amount added (Fig. 5c).

Another possible explanation for the missing TNT could be a decreasing TNT concentration of the standard solution added to the columns. What we think we added in Treatment 1 may not be what we actually added. However, eight determinations (four days $\times$ two replicates) of the aqueous solution TNT concentration on Days 38, 66, 80, and 95 (Fig. 2, 3) showed no detectable trends in the TNT concentrations (data not presented) and a relatively low coefficient of variability of $3.1 \%(2.3 \times 100 / 73.2$, Table 2$)$. So, deterioration of the standard solution is not an explanation for the missing TNT.

TNT does not bind directly to soil. Therefore, the disappearance of TNT implies degradation or transformation. The design of our experiment allows us to conclude only that the TNT was rapidly degraded or transformed to products unanalyzed for by Method 8330, perhaps coupled with the binding of the products in the soil. There is abundant evidence in the literature for the irreversible binding of TNT products in soil (Comfort et al. 1995, Grant et al. 1995, McGrath 1995, Brannon et al. 1997, Hundal et al. 1997).

\section{LITERATURE CITED}

Ayorinde, O.A., L.B. Perry, and I.K. Iskandar (1989) Use of innovative freezing technique for in-situ treatment of contaminated soils. In Proceedings of the Third International Conference on New Frontiers for Hazardous Waste Management, Pittsburgh, Pennsylvania, September 10-13, 1989, p. 489-498.

Boitnott, G.E., I.K. Iskandar, and S.A. Grant (1997) The use of frozen-ground barriers for containment and in-situ remediation of heavy-metal-contaminated soil. In Proceedings of the International Symposium on Physics, Chemistry, and Ecology of Seasonally Frozen Soils, Fairbanks, Alaska, June 10-12, 1997 (I.K. Iskandar et al., Ed.), p. 409-416. USA Cold Regions Research and Engineering Laboratory, Special Report 97-10.

Bradley, P.M., F.H. Chapelle, J.E. Landmeyer, and J.G. Schumacher (1994) Microbial transformation of nitroaromatics in surface soils and aquifer materials. $A p$ plied and Environmental Microbiology, 60: 2170-2175.

Brannon, J.M., C.B. Price, and C.A. Hayes (1997) Abiotic and biotic TNT transformations. USA Engineer Waterways Experiment Station, Vicksburg, Mississippi, Miscellaneous Paper IRRP-97-3.

Comfort, S.D., P.J. Shea, L.S. Hundal, Z. Li, B.L. Woodbury, J.L. Martin, and W.L. Powers (1995) TNT transport and fate in contaminated soil. Journal of Environmental Quality, 24: 1174-1182.

Grant, C.L., T.F. Jenkins, K.F. Myers, and E.F. McCormick (1995) Holding-time estimates for soils containing explosives residues: Comparison of fortification vs. field contamination. Environmental and Toxic Chemicals, 14: 1865-1874.

Hundal, L.S., P.J. Shea, S.D. Comfort, W.L. Powers, and J. Singh (1997) Long-term TNT sorption and bound residue formation in soil. Journal of Environmental Quality, 26(3): 896-904.

Iskandar, I.K., and F.H. Sayles (1997) Ground freezing for containment of hazardous waste: Engineering aspects. In Proceedings of the International Symposium on Physics, Chemistry, and Ecology of Seasonally Fro- 
zen Soils, Fairbanks, Alaska, June 10-12, 1997 (I.K. Iskandar et al., Ed.), p. 361-369. USA Cold Regions Research and Engineering Laboratory, Special Report 97-10.

Jenkins, T.F., C.L. Grant, G.S. Brar, P.G. Thorne, T.S. Ranney (1996) Assessment of sampling error associated with the collection and analysis of soil samples at explosives-contaminated sites. USA Cold Regions Research and Engineering Laboratory, Special Report 9615.

Marion, G.M. (1995) Freeze-thaw processes and soil chemistry. USA Cold Regions Research and Engineering Laboratory, Special Report 95-12.

McGrath, C.J. (1995) Review of formulations for processes affecting the subsurface transport of explosives. USA Engineer Waterways Experiment Station, Vicksburg, Mississippi, Technical Report IRRP-95-2.

Pennington, J.C., and W.H. Patrick, Jr. (1990) Adsorption and desorption of 2,4,6-trinitrotoluene by soils. Journal of Environmental Quality, 19: 559-567.

Selim, H.M., and I.K. Iskandar (1994) Sorption- desorption and transport of TNT and RDX in soils. USA Cold Regions Research and Engineering Laboratory, CRREL Report 94-7.

Taylor, S. (1989) Ice-water partition coefficients for RDX and TNT. USA Cold Regions Research and Engineering Laboratory, CRREL Report 89-8.

Thorne, P.G., and T.F. Jenkins (1995) Development of a field method for quantifying ammonium picrate and picric acid in soil and water. USA Cold Regions Research and Engineering Laboratory, Special Report 95-20.

U.S. Environmental Protection Agency (1994) Method 8330. Nitroaromatics and nitramines by high-performance liquid chromatography (HPLC). Revision 0, September 1994. In Test Methods for Evaluating Solid Waste, Physical/Chemical Methods, SW-846. Washington, D.C.: U.S. Department of Commerce.

Walsh, M.E., and T.F. Jenkins (1991) Development of a field screening method for RDX in soil. USA Cold Regions Research and Engineering Laboratory, Special Report 91-7. 


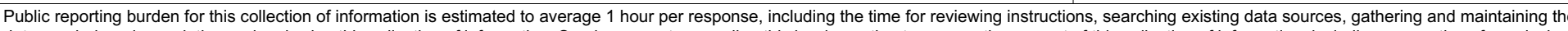

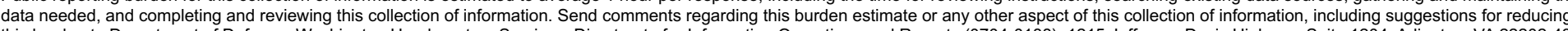

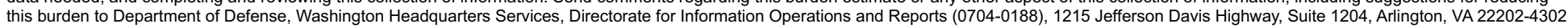

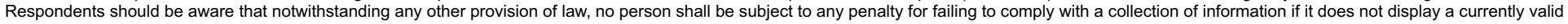
OMB control number. PLEASE DO NOT RETURN YOUR FORM TO THE ABOVE ADDRESS.
1. REPORT DATE (DD-MM-YY)
2. REPORT TYPE
3. DATES COVERED (From - To)

September 2000

Technical Report

4. TITLE AND SUBTITLE

Frozen Soil Barriers for Explosives Containment

5a. CONTRACT NUMBER

5b. GRANT NUMBER

5c. PROGRAM ELEMENT NUMBER

6. AUTHOR(S)

5d. PROJECT NUMBER

Giles M. Marion and Deborah K. Pelton

5e. TASK NUMBER

5f. WORK UNIT NUMBER

8. PERFORMING ORGANIZATION REPORT

NUMBER

U.S. Army Engineer Research and Development Center

Cold Regions Research and Engineering Laboratory

72 Lyme Road

ERDC/CRREL TR-00-19

Hanover, New Hampshire 03755-1290

10. SPONSOR / MONITOR'S ACRONYM(S)

9. SPONSORING/MONITORING AGENCY NAME(S) AND ADDRESS(ES)

Department of Defense

Washington, D.C.

11. SPONSOR / MONITOR'S REPORT NUMBER(S)

\section{DISTRIBUTION / AVAILABILITY STATEMENT}

Approved for public release; distribution is unlimited.

Available from NTIS, Springfield, Virginia 22161.

\section{SUPPLEMENTARY NOTES}

\section{ABSTRACT}

Explosives are a major contaminant of Department of Defense sites. Many uncertainties exist with respect to the mobility and stability of explosives in soils. The specific objectives of this work are to test the efficacy of frozen barriers to restrain movement of RDX, TNT, and picric acid through soils; test the concept of leaching contaminated soils above a frozen barrier as a method for soil cleanup; and compare the mobility and stability of explosives in an aged, field-contaminated soil versus a freshly contaminated soil. Two methods of adding explosives were examined. In Treatment 1, explosives were added in aqueous solution to a clean soil. In Treatment 2 , explosives from an aged, field-contaminated soil were used. In Treatment 1, where the aqueous phase explosives were added above a stable frozen barrier, there was no significant movement of explosives into the frozen barrier. There was significant movement of explosives (picric acid $>>$ $\mathrm{RDX} \approx \mathrm{TNT}$ ) into the frozen barrier in Treatment 2 . However, this is believed to have occurred when the contaminated soil was added on top of the frozen soil, which caused a temporary thawing of the frozen barrier surface. A stable frozen barrier is effective in restraining the movement of RDX, TNT, and picric acid in soils. Water extractions of the field-contaminated soil recovered $44-56 \%$ of the picric acid, $11 \%$ of the TNT, and 4-5\% of the RDX; only for the highly soluble picric acid would water extractions be a useful technique for cleanup of explosives in soils. About $88 \%$ of the TNT added in aqueous solution to Treatment 1 was missing at the end of the three-month experiment, demonstrating that there was a rapid transformation of TNT into unknown products or unextractable forms in soils.

\section{SUBJECT TERMS}

Explosives Mobility

Frozen barriers Soil

\section{SECURITY CLASSIFICATION OF:}

a. REPORT

$\mathrm{U}$

b. ABSTRACT

U

$\mathrm{U}$

17. LIMITATION OF
OF ABSTRACT
U

18. NUMBER OF PAGES

13 